\title{
Cuentos que no despiden la ficción humorística. A propósito de Cómo hablar de 10 indecible con alguien imposible, de Karolina Urbano ${ }^{1}$
}

\author{
Álvaro Bautista Cabrera \\ Doctor en letras hispánicas \\ Universidad del Valle, Cali, Colombia \\ https://orcid.org/0000-0002-0204-3923 \\ alvaro.bautista@correounivalle.edu.co
}

\author{
Recibido: 10 de abril del 2020 \\ Reseña \\ https://doi.org/10.25100/poligramas.v0i50.10509
}

\begin{abstract}
¿Cómo citar este documento en MLH? - How to quote this document in MLA?
Bautista, Álvaro. "Cuentos que no despiden la ficción humorística. A propósito de Cómo hablar de lo indecible con alguien imposible, de Karolina Urbano." Poligramas 50 (2020): n. pag.

Web. Fecha de acceso (día, mes en mayúscula y abreviado, y año).
\end{abstract}

Cuando las ficciones se fueron, quedaron los cuentos. Sin embargo, hay cuentos que recuerdan su raíz ficcional: no quieren ser solo cuentos sino cuentos sin máscaras, y para ello tienen el humor. Por ello el epígrafe del libro Cómo hablar de lo indecible con alguien imposible de Karolina Urbano, un verso atribuido a Quevedo: "Esto es amor y lo demás es risa."

El llamado literario de estos cuentos, prologados por Harold Kremer, inicia con la manera de titular de Urbano que a mi modo de ver recuerda a Macedonio Fernández (del cual hay un epígrafe en la página 49: "Yo quiero a la noche verla de día"). En el título del libro es un eco cómico hablar de lo indecible a alguien imposible, es decir, lanzar un tiro al aire que en vez de subir y caer es un mensaje que se burla de la interpretación. Este juego se repite con títulos de cuentos que son un guiño literario. Por ejemplo, "La página en blanco", cuento que teje una desaparición -en un país de desapariciones-, la desaparición de un relato, la fuga de un relato que estaba en la página y se ha escabullido quizá por pena. En el minirrelato titulado "El cuento

1 Procedencia de la reseña: Esta reseña hace parte de un interés académico individual. 
uno", el número uno se debate ante el cero por temor a ser desplazado por el número dos y termina reflexionando sobre las "personas que sueñan con un único amor" (77). En el cuento titulado "El fin del cuento", la autora materializa al mismo minirrelato como personaje que simula expurgar al narrador: "el cuento que se contaba solo, se contaba a sí mismo su propia historia, cómo había nacido... crecido... envejecido" (80).

A continuación del número, de su eventual cifra, encontramos cuentos que conjeturan combinaciones sobre los problemas del amor. El libro contiene -si no me equivoco y me pierdo en alguna página borrada- seis cuentos sobre amores imposibles (lo cual contrasta con Los amores difíciles de Calvino). Los títulos señalan diferencias entre los imposibles. Uno se llama "Amores imposibles (de nuevo)", donde el "de nuevo" parece multiplicar los imposibles. Otro se llama "Amores imposibles (sin animales)" para distinguirse de los primeros cuentos donde estos compañeros del planeta lo son también del amor y sus asuntos. Otro minirrelato agrega el número romano IV. "Amores imposibles IV" muestra que la imposibilidad va creciendo con toda posibilidad. Luego tenemos "Amores imposibles (con final feliz)", minificción en la que el final feliz consiste en una planta que recobra su verdor como indicio del cuidado del amor en la distancia. El último cuento de este tipo, "Amores imposibles VI", tiene el final que puede dar un gato que, además de gato, tiene el nombre de Merlín.

El libro multiplica sus referencias a la literatura, al cine: habla con ella como si cada historia literaria fuera un cuento a recontar. "Metamorfosis" juega con un Gregorio a quien no le impresiona lo que les pasa a las orugas, a las mariposas y renacuajos... sino que aún se siga llamando Gregorio Samsa. Otro minirrelato nos recuenta la posible expectativa de un extraterrestre por una segunda parte de una película de Spielberg. Hay una minificción que nos recuenta la brigada subterránea de Deleuze y Guattari con los rizomas. El cuento "NN" es un homenaje a aquellos fulanos y perencejos invitados también por Quevedo a sus Sueños. "Origen" es una fábula que recuerda la tradición de Esopo, pasando por Don Juan Manuel y llegando al maestro en español de las fábulas del siglo XX: Augusto Monterroso. "Saudade" es un cuento que presenta un debate entre los heterónimos de Pessoa en el que Alberto Caeiro no llega a un acuerdo con Ricardo Reis sobre la corrección de un poema y son interrumpidos cuando, a la mente del autor y poeta Pessoa, llegan "las palabras de un tal Álvaro de Campos" (48). "Daniel" es un homenaje al personaje del hijo de Piedad Bonnett del libro Lo que no tiene perdón. El cuento "El león de Natuba" retoma a un singular sujeto vendido por su padre a un 
circo y que aparece en La guerra del fin del mundo de Vargas Llosa. El cuento "El río" trae a Heráclito, pero el río le lleva la contraria al griego, y la autora hace una apuesta poética por Parménides. "Muerte total breve" es un cuento en el que la borgeseana mariposa de Chuang Tzu no sabe si es Chuang Tzu o una mariposa que sueña su muerte.

Quizá el autor que más determina estos cuentos, fábulas, minificciones, poemas -porque una poeta no olvida su lenguaje- es Monterroso. Aparece un pensativo y procrastinador de escrituras, Leopoldo, un homenaje burlón al cuento "Leopoldo y sus trabajos", que aparece en Obras completas y otros cuentos (1959). El homenaje de Karolina recuerda a aquellos que quieren escribir y no escriben, aquellos que divagan entre frases no escritas, homenaje que resalta a quien se pierde entre frases imaginadas, escritas en la mente, en el papel neuronal de la fantasía de ser escritor.

Más adelante, el libro brinda la minificción "Leopoldo, el narrador", cuento que inicia así: "Alguna vez Leopoldo intentó escribir un cuento" (70). Leopoldo buscó entre sus escasas musas, tanteó un sueño con la mariposa de Chuang Tzu, pero al despertar del extraordinario sueño, Leopoldo quedó vencido por el parecido de su texto con el minicuento de Borges y no escribió nada. El augusto asunto de Monterroso crece con el minirrelato "El globo", en el que un poeta intenta seguir el consejo de Eduardo Torres -personaje de la única novela del guatemalteco, Lo demás es silencio (1978) - en la que entramos en la prolongación del consejo de Torres de publicar un segundo libro solo si el autor mismo demuestra que su primer libro es muy malo; el poeta llega a la conclusión del desastre de su primer libro, escribe por lo tanto el segundo, lo encuaderna y lo lleva al director de una casa editorial, quien le dice que tiene muchos de esos casos y que lo mejor es que "vaya preparando el tercero" (19).

Karolina Urbano produce un conjunto de cuentos amenos, sarcásticos. Es una literatura ficcional que pone al lector, como decía Gabo de Monterroso, con las manos arriba. Con ella bien podemos decir que cuando llegaron las ficciones no huyeron los cuentos con su risa y guiño. Karolina Urbano divierte con sus juegos ficcionales y atraviesa la frontera con nuestro mundo al apretarnos con su humor un poco la garganta.

\section{Referencias}

Urbano, Karolina. Cómo hablar de lo indecible con alguien imposible. Cali: Ojo de poeta editorial. 2019. Impreso. 